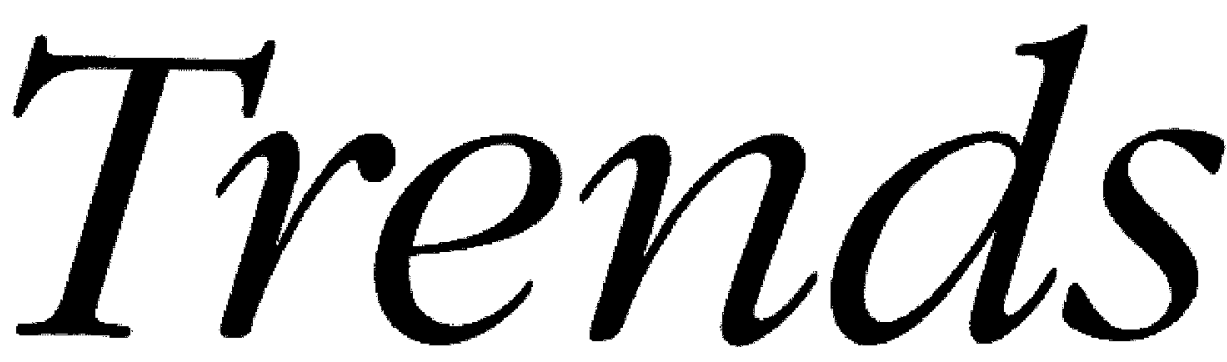

IN LAW LIBRARY MANAGEMENT AND TECHNOLOGY

Edited by Philip C. Berwick ↔ For academic, firm, corporate, and government law librarians

\title{
Happiness at Work: Rules for Employee Satisfaction and Engagement
}

By FEMI CADMus, Edward Cornell Law Librarian and Associate Dean for Library Services, Cornell University Law Library

$\mathrm{T}$ he concept of employee satisfaction and engagement is not new. Quite recently, however, there appears to be renewed interest in positive psychology, tracking what makes for happiness in general, and how this translates in the workplace. Cultivating and maintaining a climate and culture which breeds happy, motivated, and productive employees in a library setting requires hard work. A positive and productive workplace does not just happen. Happiness itself is a difficult concept to analyze and understand. What is it, and what makes for happiness? The pursuit of happiness could simply be just that - the pursuit of an elusive and unattainable ideal. While people tend to be generally happy in pleasant circumstances, others in challenging environments with none of the accoutrements of comfortable living are also able to experience happiness and satisfaction. Could it be that happiness is actually a state of mind which exists regardless of outward 


\section{Trends}

circumstances? Some recent studies have even posited that happiness is actually a genetic trait written in the DNA, and as a result some people have a propensity to be happier than others. ${ }^{\text {. }}$

Libraries are unique institutions, with jobs ranging from the tedious and mundane to intellectually stimulating, detail oriented, and challenging. Libraries by their very nature and mission have a strong service orientation centering on the needs of patrons, which are considered paramount. If this service culture is not properly managed and balanced, there is potential for burnout. In addition, the economic downturn has exacerbated stress levels due to leaner work forces taking on more responsibilities. Many academic law libraries continue to extend existing programs serving the needs of their patrons, which include faculty and students, and in some instances the general public, while paying minimal attention to the well-being of already overworked employees.

Some might question whether there is a need to be mindful of the emotional state of employees, but rather perceive it as an unnecessary distraction that's not within the set of employer responsibilities. After all, employees are paid to do their jobs, and the workplace is not a vacation retreat. It would, however, be a gross mistake to ignore the emotional well-being and health of employees, because studies have shown that content and satisfied employees are demonstrably more motivated and productive. ${ }^{2}$ Law library administrators would do well to target specific courses of action addressing issues of transparency, communication, respect and culture, amongst others, to cultivate and maintain a healthy work environment.

\section{Culture}

Work culture is probably the most important factor contributing to happiness in any organization, with a healthy work environment being the baseline requirement. There are certain ingredients which go into the mix for creating a healthy work environment, and if these are missing you will quickly discern a prevailing culture of negativity in any organization. This aura of negativity would be immediately noticeable as you entered the library and approached the information desk. Are employees unhappy, unhelpful, lethargic, disengaged or-even 
worse-cavalier and rude? These symptoms of negativity often stem from unhappiness and discontentment in the work place. The absence of the following in an organization will quickly jettison plans for a healthy work environment: respect, communication, transparency, and trust.

In contrast, a work environment in which healthy communication and transparency abounds through trust and respect is one in which employees are more easily engaged in the mission of the workplace. Employees are eager and happy to assist patrons. Flowing from this is an understanding that the organization fosters a climate where there is the freedom to make well-reasoned and informed decisions through autonomy and discretion. Freedom, discretion, and autonomy are wonderful drivers of innovation and creativity. However, both manager and employee must be careful to maintain the correct balance between autonomy and accountability.

\section{Work Life Balance}

Work life balance is touted a lot these days and means different things to different people, with generational differences playing a large role in these differing viewpoints. Some studies have shown that younger workers tend to lay more emphasis on work life balance, not wanting the demands of work to impinge on their lifestyles. However, it does appear that both younger and older workers crave the opportunity to work with flexible schedules and arrangements. ${ }^{3}$ Unfortunately, some supervisors are unduly leery of flexible arrangements, perceiving them to be unpredictable and subject to abuse. Libraries are prime candidates for flexing arrangements since hours of operation are often long, running from very early in the morning to late at night, seven days a week. Employees, after careful consultation with supervisors and human resources, should be permitted to develop flexible schedules which support library service needs. Managers at the same time must always be mindful of issues of faimess while negotiating flexible schedules. 


\section{Trends}

\section{Engagement}

All employees, regardless of generational differences, have a need to be valued and that their opinions and contributions count in an organization. This can be accomplished best with great top-down communication and feedback. Regular informal feedback is essential, and it is unwise to wait for structured moments like annual performance evaluation to provide feedback. Positive feedback and affirmation is great, and should always be provided to an employee who is trying hard, performing well and has completed projects and reached set goals. Supervisors should not, however, shy from providing constructive feedback to correct negative work attitudes or performance. This should be conducted on a one-onone basis in a private setting, and never in a public.

Meetings can be a great way to pull everyone in for a constructive exchange of ideas, as long as they are conducted efficiently and with purpose. To get more involvement in meetings, it is ideal to have them facilitated by different staff members when possible. It is also a good idea to have each staff member (or in the case of larger libraries, have a representative from each library department) provide a short summary of what is happening in their part of the library.

Committees and teams are also a great way to get staff from different parts of the library engaged in library projects. For example, the public relations team in my library is charged with marketing the library and its resources. Members are drawn from professional and support staff in both public and technical services, projects have included open houses and exhibits, and everyone on the team is involved from start to finish. It is also a good idea to mix up participation on committees by refreshing membership every year or two.

\section{Compensation and Growth Opportunities}

Interestingly, in a recent survey of the happiest companies, the company ranked the highest was not at the top for salary. ${ }^{4}$ This probably lends some credence to the saying that "it is not always about money." While employees should be paid fair and competitive wages, in line with their skills and experience, there is ample evidence that indicates that money, plus other factors, make for a happy and 
productive employee. Inducements for retention include not only good salary, but also a total compensation package with great benefits and even small perks like free coffee, lunch workshops, and bagel or donut days. These perks might appear to some to be frivolous, expensive, or downright wasteful. A successful manager cannot afford to ignore the power of seemingly small things to create a positive atmosphere. Happy and productive employees will think long and hard about taking flight from a place where they are comfortable and valued.

Most employees want growth opportunities and become easily frustrated and dissatisfied in positions which appear to go nowhere. Understanding the career goals, strengths, and expertise of individual employees is very helpful in averting the dissatisfaction and frustration that comes with the perception of being trapped in a position. Creativity in charting growth opportunities can be achieved by implementing techniques such as cross training, rotational leadership, and leadership and skills training. ${ }^{5}$ A great time to realign positions, revisit roles, and promote from within occurs when there is a vacancy due to resignation or retirement. Events of this nature provide prime opportunities to reassess the existing organizational structure and determine what current and strategic needs exist, with a view to increasing responsibilities or changing the nature of work in the newly vacant position.

\section{Support and Resources}

Near the top of the list of frustrations for many employees would be inadequate support and resources in the workplace. With the shrinking of the work force due to economic pressures, this has become even more acute. It is not surprising to hear of growing resentment from employees doing the work of several people. In order to mitigate these conditions, it is paramount that the mission of the organization be regularly evaluated. Business cannot always proceed as usual, and some processes have to be fine-tuned or eliminated. For example, with the increasing availability of digital serials, many libraries have stopped binding everything that resembles a periodical. Also, with fewer reference librarians, physical time at a reference desk can be reduced, with some libraries relying more on call reference and chat reference. 


\section{Trends}

In making these types of decisions and implementing change, it is important that everyone from the top to the bottom is involved. Valuable information about the redundancy of processes and services will come from the front lines, as long as people do not feel that their jobs are threatened. Another vital resource is support for professional development, which has in some institutions been significantly reduced because of budgetary constraints. While this is the unfortunate reality of tough economic times, there are alternative options. Such options could include in-house training and mentoring opportunities supported by skilled staff members from the library, the law school, or even the university at large, webinars, and paid time off for training and development.

Happiness in the workplace is not unattainable, but it requires a concerted plan of action and consistent effort by managers. Managers also need to take steps to make sure that their own personal and work needs are being taken care off to avert burnout. In pursuing a healthy and productive workplace, managers need to be realistic and prudent, seeking professional assistance when necessary. For example, employees with mental health or serious problems unrelated to work cannot simply be transformed into happy and productive workers by pursuing the courses of action outlined so far. Cases of this nature require drastic intervention, and professional advice should be sought from human resources to identify available resources for help. Fortunately, such situations are rare. By charting a practical course with realistic objectives (you are not creating a utopia), managers can maintain a healthy environment vital to productive, innovative, and creative work.

\section{Notes}

I. The Genetics of Happiness: Transporter of Delight, The Economist, Oct. $20 \mathrm{II}$ http://www.economist.com/node/21532247

2. For more on this subject, see Karen Dana and Ricky W. Griffin, Health and WellBeing in the Workplace: A Review and Synthesis of the Litetature, 25 J. Mgmt. 357 (1999).

3. Anick Tolbize, Generational Differences in the Workplace, Research and Training Center on Community Living, University of Minnesota (2008).

4. CareerBliss' 50 Happiest Companies for 20I2, http://www.careerbliss.com/careerbliss-50-happiest-companies-for-20I2-I3/ 


\section{Trends}

5. The rotational leadership model provides exposure for aspiring leaders to work and sometimes manage different departments in the organization. This can be a great tool in libraries where younger and emerging leaders feel trapped in roles, waiting sometimes for

interminable periods for existing managers to leave the organization through resignation, retirement, or termination.

Femi Cadmus, Edward Cornell Law Librarian and Associate Dean for Library Services ComellUniversityLaw Libraty, Ithaca,NewYotk.Enail<femi.cadmus@comell.edu>.

Trends is published by

William S. Hein \& Co, Inc.

I285 Main St. / Buffalo, NY 14209

Phone: (800) 828-757I; (7I6) 882-2600

Fax: (716) 883-8100

Email:mail@wshein.com

ISSN $0893-6773$

The complete collection of articles published

in Trends is available in HeinOnline

(http://heinonline.org)
Editor: Philip C. Berwick, Associate Dean for Information Resources

Washington University School of Law

Law Library

Campus Box 117 I

St. Louis, MO 63130

Phone: (314) 935-4042; Fax: (314) 935-7125

Email:<BERWICK@WULAW.WUSTL.EDU>

(C) 2012 by William S. Hein \& Co., Inc. 